\title{
Unconventional English in a Conventional Setting: The Genesis and Joy of the New Partridge Dictionary of Slang and Unconventional English
}

\author{
Terry Victor \\ Caerwent, Wales
}

\begin{abstract}
This article is a personal reflection on the pivotal role of Eric Partridge, how his personality and experience shaped his lexicography, and how the inherited 'spirit' of Partridge is invested in the new dictionaries that bear his name. An online version is to be published alongside an updated second edition of the New Partridge Dictionary of Slang and Unconventional English (Dalzell and Victor 2012) now in preparation. The process of translating an established dictionary model to a digital environment is not without technical challenges but these are outweighed by new opportunities to gather and define previously unclassifiable items.
\end{abstract}

\section{Introduction}

slang $n$. a type of language that consists of words and phrases that are regarded as very informal, are more common in speech than writing, and are typically restricted to a particular context or group of people. (Oxford Dictionaries Online)

In the absence of an entirely satisfactory definition for slang perhaps a metaphor will suffice.

Many words and phrases run wild and free through the landscape of domesticated language. Untamed and spirited, fierce or playful, these words are to be found in public 
packs, urban gangs and - if you know where to look - secret places. Some survive, live long and prosper underground while others seek the light of mainstream respectability; some fleeting, some feral, many are to varying degrees familiar. Broadly, these are the genera of slang and unconventional English.

dictionary $n$. a book that lists the words of a language in alphabetical order and gives their meaning, or that gives the equivalent words in a different language[.] (Oxford American Dictionary)

To extend the parallel and encompass a dictionary: if such an untamed beast of a word is captured, categorized and caged for our education and pleasure, we may well admire the zookeeper's menagerie, collected together for the improvement of public knowledge, yet all the while we are aware that the beast roaring in the enclosure is but a trapped shadow of its former wild self. Here the dictionary-maker is, obviously, a metaphorical zookeeper. Or, if slang words are butterflies, flapping wings and changing the world one hurricane at a time, then the lexicographer can be shown as a lepidopterist pinning samples onto a clean page, the beauty of butterflies reduced to one dimension, defined and displayed.

lexicography $n$. the practice of compiling dictionaries (Oxford American Dictionary)

Slang, the freshest, most spirited and vibrant genus of free language, is naturally diminished when displayed out of its context. How then to bring the unconventional and celebrate the informal within the formal conventions of a dictionary? Slang is a slippery beast, an ephemeral flutter-by; how can we ever hope to pin it down? And that, to finally bury the metaphor and build on its foundations, is the challenge for any collector and compiler of a dictionary of slang and unconventional English.

\section{In the beginning was the Partridge...}

We are currently in the middle of preparing for publication an updated edition of the New Partridge Dictionary of Slang \& Unconventional English (hereafter NPDSUE, NPDSUE\#1 [1 st ed.] and NPDSUE\#2 [forthcoming 2nd ed.]) so this is the perfect time to look back over the process and reflect on how we got here. Whilst I ought to be engaged in proof-checking, it is a natural and easy diversion to consider the principles and philosophy of our work so far. ${ }^{1}$ It would, perhaps, be as well, early on in this document, to declare that freelance lexicography is not the primary occupation of either of the 'we' at the top of this para. For us the darker and more wickedly playful temptations of our language are the hookers of our obsessions and scholarship. 'Tom Dalzell is a lawyer who moonlights in an extremely serious way as a slang collector and author' (NPDSUE\#1: dust jacket blurb). I am the other half. This brief biog heads up my Twitter ${ }^{\mathrm{TM}}$ feed (@TheTerryVictor): actor,writer, director, lexicographer, storyteller, anti-censorship campaigner, political animal; married, bespectacled, mostly 
happy.... Equally diligent, our differences are reflected in our approach to the work: Tom is clear-sighted, practical and pragmatic, while I tend to be emotionally involved with the words, always looking for a story arc. The greater third of the sum of our two halves (I know that doesn't add up and I am one hundred and ten per cent happy about that) is our publisher, Routledge. The company, represented by the people with whom we have dealings in that greater enterprise, is an absolutely essential element of the work and these recollections. You will have to wait for the new Acknowledgements in August 2012 for fuller details. What follows here is a personal reflection, my POV (as we say in the acting business). Very much my own point of view.

It is well-known, perhaps to the point of truism, that all dictionaries build on the work of others. One well-known slang-lexicographer (not in any way attached to our project and quoted here in some kind of confidence) candidly describes this process of dictionary building as 'reverse engineering'. The NPDSUE does indeed stand on the shoulders of a giant (to adapt the original ${ }^{2}$ to the singular). The Partridge in the title, literally at the head of the NPDSUE, is Eric Partridge (1894-1979). In his turn he had built on the works of, as instances, Francis Grose (1785), Ducange Anglicus (1857), John Camden Hotten (1865), and the 'expansible framework' of Farmer \& Henley (1890-1904), among others, but it is in the forging of Partridge's own A Dictionary of Slang and Unconventional English (1937) that our current work began, and from whence we developed both form and personality.

LEXICO'GRAPHER. n.s. [...] a writer of dictionaries, a harmless drudge, that busies himself in tracing the original, and detailing the signification of words. (Johnson 1755)

Eric Partridge was a 'harmless drudge' in the Johnsonian tradition: a lexicographer whose personality and experience is writ large in the detail. ${ }^{3}$ Partridge's work is not selfless; his autobiography 'cheerfully and incorrigibly serving a life sentence' can be discerned throughout his Dictionary of Slang and Unconventional English pages.

In brief, for those who have not yet had the pleasure of his company, Eric Honeywood Partridge was born in New Zealand in 1894. The family moved to Brisbane, Australia, when he was twelve or thirteen. He studied Classics then French and English at the University of Queensland, subsequently moving to the UK as Queensland Travelling Fellow at Balliol College, Oxford. In the meantime he saw military service during the First World War as an Australian infantryman (an indisputably slang-rich experience, captured in Songs and Slang of the British Soldier: 1914-1918 [Brophy and Partridge 1930]), at Gallipoli, and was wounded in action in France. During the Second World War (Partridge 1948) he served first in the British Army Education Corps, then in the RAF's correspondence department (Partridge 1945). Between the wars he founded the Scholartis Press, with offices at 30 Museum Street, London WC1 convenient for the British Museum Library where, famously, - from 1923 - he had residency at desk K1 (sadly, reconstruction has not preserved his place). Scholar, soldier, novelist, lexicographer, publisher, father, tennis player and philologist... that's the Partridge of our title. 'Our word partridge comes from the Old French pertis which comes from the Latin perdix which comes from the Greek verb 
perdesthai which means fart, because that's what a partridge sounds like when it flies' (Forsyth 2011). Our Partridge flew and in so doing, like the mythical butterfly, created a flap that changed the academic landscape across the world from where he began, but 'like most great - as opposed to merely famous - men, he was modest and humble' (Partridge 1963).

The Songs and Slang of the British Soldier and his annotated edition of Francis Grose's Classical Dictionary of the Vulgar Tongue led to his association with the publisher George Routledge (of George Routledge Ltd, subsequently of Routledge and Kegan Paul, which now survives in the Routledge imprint at Taylor \& Francis) and resulted in a commission to compile A Dictionary of Slang and Contemporary English [1937]. Some sixty years later, when the 8th edition had already more than 10 years under its belt (it is still in print), a commercial need to keep the Partridge 'brand' alive provided Routledge with the impetus to commission, what was at that time planned to be, a 9th edition.

\author{
badda bing; bada-bing; ba-da-bing \\ used as an embellishing intensifier US \\ The variations are nearly endless \\ - You've got get up close like this and bada-bing! You blow their brains all over your nice \\ Ivy League suit. - Mario Puzo and Francis Ford Coppola, The Godfather, 1972 \\ - And on this farm he shot some guys. Ba-da-bip, ba-da-bing, ba-da-boom. - The Usual \\ Suspects, 1995 \\ - Badda-bing. Badda-bang. Ira Steven Behr and Hans Beimier, Star Trek,1999 \\ - It was cake - 8 cars. Badda-bing. - Gone in 60 Seconds, 2000 \\ - [T]hey were drinking shorts and, of course, they were surrounded by fawning, gorgeous \\ young women. As Tony might say: "It's been that way since time immemorial." Ba-da- \\ bing indeed! - The Guardian, 16th September 2002 (NPDSUE\#1)
}

The usual suspects were rounded up (this is not that long after the movie The Usual Suspects was released): ba-da-bip, ba-da bing, ba-da boom! the American slangophile and glossarist Tom Dalzell ${ }^{4}$ was identified as Keyzer Soze. My own route to the project was, as an actor, via a first meeting with Partridge in the pages of Shakespeare's Bawdy (Partridge 1955) and later, as a slang collector, by serendipitous acquaintance with Tom.

The legacy of Partridge is a huge responsibility: 'There is far more imagination and enthusiasm in the making of a good dictionary than the average novel' (Partridge 1963). We are the privileged inheritors of his 'brand', not pretenders to his throne. The above digression into life histories by way of reference to contemporary culture is not tangential. Partridge (1963) wrote: ' $[\mathrm{I}] \mathrm{t}$ is the course of my life which, allied to a natural propensity to original sin, has made a lexicographer out of me.' Any work in which personality is invested is subject to autobiography, and a recognised purpose of the NPDSUE, therefore, is to keep the spirit of Partridge alive whilst building on his work. In the genesis of the NPDSUE that was a relatively easy decision to make. Others would prove far more complex. 


\section{Criteria for inclusion}

This dictionary, at which I have worked harder than (I hope, but would not swear) I shall ever work again and which incorporates the results of a close observation of colloquial speech for many years, is designed to form a humble companion to the monumental Oxford English Dictionary from which I am proud to have learnt a very great amount. (Partridge 1937: Preface, November 11th 1936)

In his original plan for the dictionary Eric Partridge had limited his scope to 'Great Britain and her Dominions'. At the time of first writing this may have been a convenience or necessity or, perhaps, geopolitically relevant or simply a requirement of George Routledge. By the time the 9th edition came under discussion, that narrow worldview was found to be by no means helpful or appropriate. Indeed, by the mid-20th century, other of Partridge's works had deliberately widened his focus to include both 'British \& American' (Partridge 1949) but the DSUE had remained firmly set on its original course: 'Colloquialisms and Catch Phrases, Fossilised Jokes and Puns, General Nicknames and such Americanisms as have been naturalised'. In 1999, with British and American editors now on board, the decision was taken that the 9th should include slang and unconventional English from anywhere in the English-speaking world, which meant that the DSUE would need to be rebuilt from the ground up. An instant and immediately recognised consequence was that the potential word list would be too vast for any reasonable extent.

It is generally accepted that Partridge, although occasionally archaic in tone, is at his strongest while dealing with matters of which he had direct experience or contemporary interest: two World Wars, wine, women and song, as instances. He was a man of his time, as described above, who clearly recognised the need to keep up to date, but postwar youth and its cultural preoccupations were not necessarily of interest to him and that is reflected in his coverage. Paul Beale, immediate inheritor/editor of the 8 th, wrote in 1982, in his Preface,

that the Dictionary should try to deal mainly with British English stems from my decision to ignore, except in minor references, any mention of the jargons generated by the two great imported fads that have swept the country while the work was in preparation: those of skateboarding and Citizens' Band radio. Neither, so far as I am aware, has had any real impact on our 'normal' unconventional English; both are completely derivative.

The current editors are both nineteen-fifties'-born teenagers of the sixties: sex and drugs and rock and roll (cf. Dury 1977) are our 'wine, women and song' birthright. We have no wish to control the language in our dictionary. We would hope to celebrate all the words of our times. Therefore, to maintain the integrity of Partridge's original yet give scope for a new work the criteria for inclusion in the 9th edition was limited to terms or phrases in use post-1945.

With the general terms of coverage and a more or less precise timeframe established, the third and final major consideration in our criteria was usage: essentially, 
when examining a term for inclusion, is it slang? Which brought us bang up against the big question: what is slang? Slang is 'a peculiar kind of vagabond language, always hanging on the outskirts of legitimate speech, but continually straying or forcing its way into the most respectable company' (Greenough and Kittredge 1901: 55). Or, slang is 'a kind of language occurring chiefly in casual and playful speech, made up typically of short-lived coinages and figures of speech that are deliberately used in place of standard terms for added raciness, humor, irreverence, or other effect' (AHD4). Fortunately, an accurate definition of slang is one definition we could sidestep; in our dictionary we are dealing with the conveniently indeterminate, inherited categories slang and unconventional English:

Rather than focus too intently on a precise definition of slang or on whether a given entry is slang, jargon or colloquial English, we take full advantage of the wide net cast by Partridge when he chose to record 'slang and unconventional English' instead of just slang, which is, after all, without any settled test of purity. (NPDSUE\#1: ix)

We simply defined our standard for inclusion as

all unconventional English that has been used with the purpose or effect of either lowering the formality of communication and reducing solemnity and/or identifying status or group or putting oneself in tune with one's company. (NPDSUE\#1: ix)

The inclusion criteria agreed for the DSUE's proposed 9th edition: (1) slang or unconventional English, (2) used anywhere in the English-speaking world and (3) after 1945. The overarching principle: to invest the work with the spirit, scholarship and joy in language that is evident in the writings of Eric Partridge.

headword $n$. a word which begins a separate entry in a reference work. [Oxford Dictionaries Online]

In much serious lexicography the basic entry appears to be the be all and end all. Chambers' occasional Johnsonian definitions aside, ${ }^{5}$ the greyed-out pages of many dictionaries appear to deny the myriad pleasures and excitement of the language within. That process, we decided, would be nowhere near (good) enough for the 9th edition of the DSUE. We would enjoy the playfulness of the words in our lexicon and in the tradition (if not the socio-political context) of Eric Partridge we would wear our authorial hearts on our sleeves.

Finally, with these major strategies determined, we came to a realisation: this could no longer simply be a 9 th edition. It would have to be the 1 st edition of something fresh. 


\section{The New Partridge}

The workload, starting from not quite scratch, was dauntingly enormous. For myself, I certainly didn't realise how much work it takes to compile a dictionary. Enthusiasm and bloody-mindedness saw us through. A comprehensive style guide was developed: 'The definitions and commentaries will be written in conventional English, and the tone will be discursive and noticeably less formal and formulaic than standard dictionary format protocols'. We grappled with questions of alphabeticization, capitalization, alternate spelling, cross-referencing, etc: all this, and much more of this, is dealt with in the Preface to the NPDSUE.

A practical process was devised for the compilation and storage of entries: headwords were created on personal computers and uploaded, as and when complete or convenient, to an online data storage facility designed to our requirements. Without question Tom Dalzell and I are wordy characters - we have been known to complete each other's punch lines and Zappa lyrics - but, as neither of us has a formal academic background in linguistics, we were finding our way as we went along a very steep learning curve. Most of the time it was a pleasure but some days were hell.

For me the greatest pleasure of slang lexicography is in the hunt (first catch your headword!); the eclectic reading and discovery of supporting citations. Even here and now, casually browsing the NPDSUE as I write, I find myself caught up in the social narrative revealed by a single entry. Flicking pages my thumb has just landed on the following headword (bottom right on a right-hand page), the first of fifteen listed senses:

\section{blue noun}

1. methylated spirits as an alcoholic drink UK

From the colour of the fluid.

- The usual practice is to extend it (metal polish) with lemonade or a shot of blue. Geoffrey Fletcher, Down Among the Meths Men, p.17, 1966

- [O]n a cold night, if you lie down, take a drink of the blue, and then pull the collar of your coat over your head, "it keeps you warm". - Robin Page, Down Among the Dossers, p.122, 1973

- They [vagrant alcoholics] subsist on a diet of methylated spirits (jake or the blue), surgical spirit (surge or the white) and other forms of crude alcohol. - Peter Ackroyd, London The Biography, p.359, 2000

True, linguistically, this use of blue may not be much of a discovery (it's blue; therefore it's blue) but as a piece of slang with social weight it has, for me, great added value. The NPDSUE is a compendium of many such horrors and delights: that is our dictionary's dramatic subtext and part of the Partridge tradition. In this particular instance my (re-)discovery has the further worth of being randomly selected. 'For most of us, a dictionary is hardly a book to read; a good dictionary, however, is a book to browse in' (Partridge 1963).

The practical genesis - perhaps gestation is a better word - of the New Partridge was from 1999 to 2005. We were inheritors of the old and beneficiaries of the Internet, 
dated and clunky as that dial-up generation now seems. From the word go (15 noun senses, 10 verb senses, too many phrases to be bothered to count, and one exclamation!) through compilation, proof-reading, editing and heartfelt discussions on design and marketing, all the way to the publication party at Dr Johnson's House, the NPDSUE was the vehicle that took me on one of the most exciting journeys of my life. But now, as we prepare a 2 nd revised edition, with a bit of experience under our corporate belt, I would say that our life in slang is getting really interesting.

It is natural for us, as conservators of words, to concentrate on practical matters and measure content in a traditionally conservative, hardback way. However, the faster new and errant slang appears, the sooner we will be faced with issues of extent. Given that, the story so far is just my preamble.

\section{The New Partridge \#2 (not so slight return)}

Come August 2012, when Routledge publishes the 2nd revised edition of the New Partridge Dictionary of Slang and Unconventional English, a mere seven years will have passed since its first appearance or, more dramatically, only four years between the published date of NPDSUE\#1 and the contracting for NPDSUE\#2. Four years, in which time the Concise NPDSUE [2008] and a couple of smaller volumes (Dalzell and Victor 2008a, 2008b) drawn from the NPDSUE database have appeared. That's a pretty short space of time (in academic publishing) and must, in part at least, reflect the speed at which our modern world is moving. With the benefits of Google and hindsight, the changes in our dictionary's landscape are easily apparent. The mention of Google is hardly accidental: the seeming near-ubiquity of the Internet (in 2011 the number of Internet users worldwide has reached the two billion mark; ${ }^{6}$ almost one in three of the global population), especially of broadband and superfast broadband, with its search engines, Usenet and social networking, has changed the texture of society. Without question, it has had a far-reaching effect on the societies in which the various unconventional Englishes of the world hold sway. The Internet has changed the means by which we conduct the social intercourse of our lives and this, in turn, has impacted on the creation of new slang and unconventional English. Without giving serious consideration to user-compiled online 'dictionaries' (although it would be disingenuous to suggest that such sites have no value for the slang-collector) the Internet's general effect on language has been profound, both in coinage and distribution.

The first and perhaps surprising observation to make about 'online language' is that there is no such thing, at least in the most obvious sense that here is a homogenous online culture that shares a single jargon. Instead there are multiple communities online, using the medium for a variety of reasons, and talking in a wide range of dialects which, although they share some features, can fairly easily be distinguished. (Dent 2006: 47) 
In consequence, and in parallel, the Internet has had a radical effect on methods of dictionary compilation and delivery, as well as presenting slang collectors with endless research opportunities previously denied.

\section{fur pile noun}

(in the FURRY and PLUSHIE subculture) a group of furries lying on top of each other

Also used in a verb sense.

- Alex jumps on! Fur Pile! alt.lifestyle.furry 20th March 1997

- If someone asks if you want to 'fur pile' then they are enquiring if you want to lie on top of a group of furries and paw each other affectionately. Tim Fountain Rude Britannia p.156, 2008

The fur pile entry (taken from the forthcoming NPDSUE\#2) is a useful illustration. The earliest recorded use thus far (20th March 1997) was written before work on the first edition actually began. However, even had we discovered the term at that time and considered it valid for inclusion, during that first period of compilation we were extremely cautious in our use of Internet newsgroups and the like as an academic resource, preferring to rely on traditional 'respectable' media.

Since then, of course, the content of Internet groups has become easier to interrogate: Google Groups track back into the1980s, for instance. Easier research has, consequently, advanced antedating and that, in turn, has tended to validate items from the relatively new medium.

The Internet has given fur pile (and much else) currency. It is probable that people with a specific interest in dressing up in adult-sized animal costumes (for fun and pleasure - not as a requirement of advertising or mascot-work) have been living relatively closeted lives for many years, a presumption supported by the available technology of needle, cotton and fake fur fabric when counted against the lack of vocabulary. It is equally reasonable to surmise that those with such a distinctly minority interest or fetish, especially a sexual fetish (however mild), would have - and not so very long ago - struggled to find and form a community of like-minded specialists. Did pre-Internet plushies and furries lurk wishfully and wistfully in haberdashery departments? Pre-Internet, if you were the only one (whatever that one may be) in your street, how would you connect with others? Or even know that others exist? The Internet has facilitated and, arguably, promoted such alt.lifestyle groupings.

In My Other Self, Angela Lewis, PhD, quotes Nik, a cannibal fantasist:

How all of this felt during most of my life...in a word, lonely. There was no Internet when I was growing up and this is not the sort of subject anyone would feel comfortable talking about (face-to-face) with anyone else. Especially not a confused kid and definitely not with my parents! For most of my life, I thought I was a complete freak and probably a borderline nut-job. It's embarrassing, scary, and very lonely. (Lewis 2010: 2)

Dr Lewis goes on to observe that 'this situation has eased since the cyber-revolution brought us the Internet [...] a very simple way for people whose sexual interests are not 
mainstream to connect with others who share their interests - and discover that in the words of Dafyd [sic] from Little Britain, they are "not the only gay in the village".'

As all closed groups (and this is especially true of unconventional single-interest groups) must depend to some degree on a discreet mutual language, a private slang although, bearing in mind its Chaucerian origins as birdsong, perhaps jargon would be more apt for plushies and their vocabulary - it is inevitable, even desirable, that more minority slangs will develop.

Another, closely related example, taken from NPDSUE\#2:

\section{yiff noun}

(within the FURRY and PLUSHIE fetish subculture) sexual activity; also used as an expression of interest in sex in anthropomorphic context

- On Furrymuck, some characters have defined the "yiff" sound to mean a request for sex. alt.fan.furry 2nd August 1993

- The most common reason for two furs to "yiff" is simply to relieve sexual pressure. WikiFur 1st October 2010

There is an unproven suggestion that a human 'fox' uttered the cry yiff (somewhere between a yip and a woof) in imitation of the real thing. Whatever its true etymology, the term has caught on - in certain insider circles. The search for, and gathering of, such new and unconventional language took us on some interesting pathways, not just into the foothills of fetish, but the discovery of yiff was one of the true joys of my recent word-hunting (although, I confess, I have not as yet managed to drop it into a conversation).

Whilst offering no opinion on the physical activities that bind these groups (ours is not to judge, censor, nor reason why), we have treated words created and discovered within these narrowly focused and closed-communities with caution. 'There is a tendency for people in chatrooms, game-environments and computing laboratories to develop a consciously idiosyncratic (not to say eccentric) vocabulary, which acts as a badge of identity for an individual group' (Crystal 2004: viii). We have tried to focus on terms used by communities that are identified by a common interest rather than that restricted to the subsets that exist within those groupings.

Meanwhile conventional slang - not quite the oxymoron it appears - continues to grow apace. 'While not all slang is ephemeral, most is; likewise, youth itself is fleeting and transitory. Combine the passing nature of youth and the passing nature of slang and the result is a quickly passing youth slang' (Dalzell 2010: xi). Teen slang is a hothouse for the most ephemeral language; it almost always meets similar social requirements with reinvention. In our online, socially networked, blogging society it may be that this generational slang is generated no quicker than it ever was but it surely spreads its influence wider and faster than previously cool kids could ever have imagined. Tomoz is out of date already. Soz. 
soz adjective

sorry

- i am soz i am vague but new to all this - Nick 'The database Guy' microsoft.public.access.formscoding, 18th August 2006

- - Lucy Van Amerongen, The A-Z of Teen Talk, p.29, 2007

- So soz to everyone I angered with meh endless rantz - James-015 bfmracing.net. 3rd July 2009 (NPDSUE\#2)

\section{tomoz; tomozza; tomozzer noun}

tomorrow UK

- DL is on tomoz and I get to see the G'Kar knife bit that was cut by C4 - Jools Hodgkinson uk.media.tv.sf.babylon5 28th October 1995

- I've landed in a rather chilly and very wet Barcelona. Check in and flop onthe bed, I reckon. Tomozzer will be long and tiring. Stephen Fry @ stephenfry 15th February 2011 (NPDSUE\#2)

In this latest trawl through the undercurrents of unconventional English we have encountered other developments in slang of, arguably, greater significance to slang and unconventional English than the enhanced opportunities to coin and share considered above. During the compilations of NPDSUEs \#1 and, especially, \#2 we have witnessed a noteworthy evolutionary change in the nature of slang:

the unprecedented migration of slang from the spoken word to the written word as a result of the exponential growth of electronic communication, social networking and microblogging websites; from AOL's Instant Message in the mid 1990s, to texting through SMS in the early 2000s, the commercial launch of Facebook ${ }^{\mathrm{TM}}$ in 2004 and the 2006 introduction of Twitter ${ }^{\mathrm{TM}}$. These new social media have turned teenagers and young adults, in particular, into writers. The social media are a fertile breeding ground for informal, nonstandard, unconventional English, and they have in large part turned slang-talking users into slang writers. (NPDSUE\#2: front matter)

With exceptions to prove the rule (this is slang, after all) the migration is one-way: a non-standard vocabulary of unconventional and exaggeraaaated spellings, initialisms, \$ymbol\$ and random cApitAls for embellishment, phonetic puns, emoticons, and other elements that are, obviously, not all that easy to translate into speech.

Let's look at Awesoooooome ; $3 x x{ }^{7}$ quoted in the introductory matter of NPDSUE\#2, recorded in Facebook ${ }^{\mathrm{TM}}$. The first component, Awesoooooome, is a deliberate misspelling of a standard term in the teen vernacular.

awesome adjective

great, excellent US 1975

An informal variation of the conventional sense. (NPDSUE\#1: excerpt of entry)

The purpose of this variant spelling is the intensification of the existing superlative; excellent is not good enough, apparently. The same effect is achieved in speech by 
stressing or stretching the delivery of a syllable. In this sample the $o$ appears six times, five times more than strictly necessary, but it must be unlikely that the writer was counting or even conforming to a regular in-group pattern; she was simply hitting the $o$ key until her desired effect had been achieved. The textual emoticon ;3 is unfamiliar and apparently used here as a signature. ${ }^{8}$ The use of $x x x$ for kiss kiss kiss is, obviously, very familiar: the kisses on the bottom of informal correspondence.

The slangy and rebellious impression first given by Awesoooooome ;3 xxx is actually, as we can see, little more than a veneer; more to do with signifying inclusion within the user's group than compelling exclusion with impenetrable slang. Except as illustration of unconventional style such citations challenge the conventional structure of a dictionary: is awesoooooome a headword or a variation? Or even sufficiently compelling to warrant inclusion? 'After generations on the street, slang has found a home in writing, in the glow of a handheld or laptop or desktop screen' (NPDSUE\#2: front matter). At the same time that more slang is developing in written form we are finding that it is actually harder to tackle some of those particular items in definitive form. Faced with easier-to-find samples, we are now faced with the stumbling block of recording the rules of variation rather than the variations themselves.

\section{The New Partridge Online}

Given all of the above, what would Partridge do? Our boffy answer (and, if I'm honest, ambition) was that the New Partridge would move with the times and lead the way.

\section{boffy adjective}

clever

After BOFFIN

- She was good, she was boffy (she was in the sixth form for Christ's sake: how boffy was that?) - Danny King, School for Scumbags, p.14, July 2007

- [C]lever kids can be seen as a bit geeky or a bit boffy. - usingenglish.com/forum/askteacher, 27th July 2009 (NPDSUE\#2)

The next step would be to create a fully-functioning online dictionary of slang and unconventional English. Obviously, far easier said than done but, here too, the 'monumental Oxford English Dictionary', now well-established online, has led the way.

Our software also allows editors to work remotely: an editor in the USA, for example, can make changes to a definition which are instantly accessible to colleagues in the UK. And as well as the actual words and definitions, modern dictionaries contain other electronic data which a reader doesn't see, data which enables the dictionary content to be developed in many different ways[.]' (Frequently Asked Questions, Oxford Dictionaries Online)

To achieve our ends, we reasoned, it would be necessary to: (1) create and build a flexible search function, (2) clean up the database, (3) second-guess future 
requirements, (4) imagine new possibilities, and (5) have it all up and running for August 2012, to launch online alongside the revised two-volume hardback edition.

Dictionaries are reference books. People consult them to find out information about words. We must assume that compilers of dictionaries - lexicographers - include information that they know or expect people will want to look up. What we cannot assume, however, is that lexicographers will exclude information that they might expect users will not want to look up. A dictionary is more than just a reference book; it is also a (partial) record of a language. Any dictionary contains information that few, if any, users will want to access. (Jackson 2002)

The Internet offers an interface that allows all users to define and search themed lists; the alphabet can no longer be the sole register.

We can also build in sophisticated searching facilities which allow a user to browse within specific linguistic or semantic categories or personalize their experience by creating 'subdictionaries' of their own. (Frequently Asked Questions, Oxford Dictionaries Online)

This is a whole new ball game - I searched online and found the Oxford quotation in a matter of moments.

We commenced with a revision of the online editor. The major physical change for us homeworkers is that this time all of our work has been online. The thinking is that this new working environment is both more flexible and secure. Most of the functions were retained from the first edition. As with any new system, it settled down as we got used to it - as we became more flexible and secure.

\section{Create and build a flexible search function}

For the construction of the NPDSUE\#1 we had included classification key words in a drop-down box. This information was uploaded and held in the background of each entry, to facilitate any simple breakdown or search we, as editors, might later require: crime, rhyming slang, sex, transport, etc. It is readily apparent that for NPDSUE\#2 the search criteria must attempt to allow for the far more specific needs of any individual dictionary user.

taxonomy $\square$ n. chiefly Biology the branch of science concerned with classification. scheme of classification. (COED11)

'[T]axonomy is the creation of order and ranking, and taxonomists - who figure out how things stand in relationship to each other - will be in increasing demand as the Internet creates the need for structure and organizational wisdom' (Popcorn and Hanft 2001). The taxonomy of slang is not at all clear-cut: all human life is here and slang, in its nature, rails against conformity. Its instinct and purpose is to rebel against any common sense hierarchical structure. The elements in our classification (variously 
known to scientists as taxa or facets), often want to sit at more than one table. Rhyming slang, UK, sex, noun, phrase and crime, for instance, may all have claim on a single term; multiple hierarchies abound. It's a mammoth task we've taken on: every sense of every multi-faceted headword is being individually tagged - in increments of 5,000. The desired result is that the New Partridge Online will break fresh ground for academically-founded slang dictionaries. The updated edition, when it is published next August, will appear in traditional hardback format as well as online. One of the joys of going cyber is that the word list need no longer be trapped between boards, subject to, and constrained by, the limitations of extent. The faster that new and errant slang appears, the sooner the traditional hardback format will be faced with issues of extent.

The structure of any dictionary needs to be uncompromisingly secure: every headword in its place and every entry conforming to a strictly observed pattern. Now, however, in a digital environment, the interactive processes of searching and random browsing need no longer be subject to the formality of order that we have always known. The Internet-based user of the New Partridge will be free to let his or her mind wander, to flit without regard for the weight of well-ordered slang that would otherwise interrupt or formalise the browsing experience. In that respect, if no other, the user and the compiler are brought closer together. Collecting together a dictionary's wordlist is a largely random act, subject to fortune or chance, informed only by your choice of where to look. It is true that, to some degree, you can 'reverse engineer' your own luck but, even so, slang lexicography, like dictionary-grazing, is the perfect occupation for a grasshopper mind: within any subject area of interest the exploring mind can leap from point to point. That's me, since I was knee-high to a grasshopper; this paragraph alone is sufficient proof of that credential - although, perhaps, a butterfly (a metaphorical butterfly) would be more apt than a grasshopper. Indeed, true to the spirit of Partridge, if the logic behind this essay appears to leap all over the place, it is a reflection of my personality: I am concentrating on the genesis and joys of the NPDSUE and there is no straight (7 nouns, 10 adjectives, 1 exclamation!) route through our dictionary. That's why creating and managing the taxonomy is such a challenging responsibility. The process of building the taxonomy is in train at the time of this writing: lists of words are flitting back and forth across the Atlantic as we make sense of it. One email in today's inbox contains the phrase 'cascading up is the big one'. It is.

\section{Clean up the database}

Two thirds of the way into the NPDSUE\#1 we could no longer avoid the fact that we had far too many headwords for the available pages. Way too much material but not a problem. Technically, it was a relatively easy operation for the editors to suppress fields and reject entries. If memory serves, we had to lose two or three entries per page; it was an occasionally painful process. Overcoming qualms, we simply clicked the mouse on a couple of on-screen buttons and the designated contents didn't appear in the finished work. The data, however, didn't go away. It's sitting there now, somewhere in 
cyberspace, under discussion, awaiting a second chance. The updated New Partridge could see those lost words reinstated as a sort of bonus for online users.

The castaway entries are still in need of final editing and the decision is yet to be made; it's a live issue. I mention it here to give a practical illustration of the possibilities of a dictionary without the limitations of the printed page, a dictionary that exists as a version of, and alongside a, conventional book. I need to take a moment to consider my relationship with the old and the new.

Emotionally I am with the book. As I write, I am surrounded by books. I have a mug of hot coffee in front of me: the mug is decorated with a cartoon illustration and philosophy/caption: THERE'S NO SUCH THING AS TOO MANY BOOKS! At the same time I am physically in touch with my computer. I am just a get-up-and-reach away from my library of something in the region of 3,000 items but a mere click away from the Internet. My utopian understanding of the Internet's philosophy/raisons d'être: there is no such thing as too much knowledge or information. Libraries and bookshelves have been my adventure playground. Instinctively, I trust the contents of a book over the contents of the Internet - which, I know, is foolish. The NPDSUE\#2 proves the point: both versions, digital and print, can be trusted equally. Depth of coverage vs. searchability: books provide many happy hours of ponderous research, while the Internet can deliver the same results in a few (or less) interesting minutes. An Internet vs Books debate however is, at best, invidious if it is the content that is at issue. Books, of course, are an aesthetic delight. I love the heft and smell of them. On the other hand, my bright and shiny laptop, an object of desire, weighs about the same or less than one volume of the two-volume NPDSUE - and, without any sense of irony, I use the laptop to buy books. The headwords highlighted herein have been sourced in both media, as I found it convenient. Heart over head: the book. Head over heart: the future is digital, convenience will prevail. For our dictionary, it's the message not the medium that counts. Net or book, book or net: it's just horses for courses, take your pick. I will have a copy of the New Partridge in both media. Maybe in a year's time I will be less confused. OK, maybe ten.

\section{Second-guess future requirements}

I am writing this at home in Wales, where I am subject to several layers of governmental concern but, lacking any cachet of celebrity that might tempt the redtops, I am substantially free to live my life in private. The would-be guardians of my morals and censors of my freedom, those who believe and propound that too much knowledge or information is a decidedly bad thing, are currently nipping at the edges of the warp and weft of UK society, pulling at threads. Despite their best intentions, the fabric of this country, although wearing a little thin in places, is not, as yet, coming unravelled. Informal language is, if anything, less constrained than in the past.

Nevertheless, the more we use technology to communicate and the more we need discreet or socially inclusive/exclusive language, the greater are the requirements that 
can be expected to be made of a slang dictionary. From a reasonably secure UK vantage, my world-view is biased; world English is, however, and will continue to be, subject to varying cultural pressures. If, as is likely, technology increasingly threatens, or provides the excuse to threaten, individuals' privacy, then there will be an evergreater requirement for more coded and unconventional language. Looking forward then, trying to account for the blurring edges of social acceptability on the move, how can the New Partridge be made future-proof? It's now six years since the last NPDSUE: how long can it be until the weight of new words is once again irresistible?

My best guess is that a drip drip drip of incremental growth will build an everexpanding online NPDSUE database. Where that will leave the hardback is anybody's guess. The wider debate on the future of the book continues elsewhere; no doubt you can read all about it on your Kindle ${ }^{\mathrm{TM}}$. As lexicographers, however, our primary attention must be given to the dictionary database. The form in which it is published, while of profound personal interest, is a professional matter for publishers. A question I had, and still have to, ask myself was to what purpose does a slang dictionary exist?, not what is the purpose of a slang dictionary? - the latter is just a question of definition. My answer to the philosophical enfolds the definite purpose: a dictionary of slang and unconventional English stands between generations as a gateway to learning, offering each new generation definitions of the old. For me Eric Partridge was the gatekeeper inviting me in. I hope he would agree. In whatever ways the next generations wish to consume a dictionary what should be of primary importance is the message not the medium. That established (to my satisfaction, at least), and the taxonomy in place, second-guessing the future becomes a simple assumption that things are the same as they ever were, only more so. Plus ça change plus c'est la même chose, I suppose.

\section{Imagine new possibilities}

It would be easy to conclude that, in the various ways noted above, the NPDSUE\#2 is just business as usual, only more so. If that were so, it would certainly be enough to satisfy the demands made of it. However, as the New Partridge evolves into an expansible framework beyond the possible imaginings of Farmer and Henley, it has become a whole new playground of possibilities.

By the time of the DSUE's 5th edition's publication (1961), the Dictionary had been supplemented by a second volume of nearly 400 pages. For the 8 th edition Beale oversaw the 'the conflation of the original text of the first (1937) edition with all the subsequent Addenda...'. In addition he compiled and edited a substantial Appendix which appears in the final pages of the 1400 page book. The Appendix commences with a charting of the evolution of the phonetic alphabet and concludes with a paragraph that lists Women in C.18 Slang. The Appendix is a treasure trove of glossaries and commentaries on a wide variety of topics that Paul Beale couldn't find space for in the main body of the dictionary, including (my lucky-dip selection) Australian Underworld Terms Current in 1975, Drinks, Drunkenness, Moving-Picture Slang, Parlyaree, 
Prisoner-of-War Slang, Public and Grammar School Slang in 1968, Railwaymen's Slang, Spanglish, Tiddlywinks and so on. Interesting bits and entertaining pieces that enrich the whole but, for Partridge (and Beale), restricted by the limits of a conventional book, there was no other way to share their delights with the dictionary's reader.

In an online environment an Appendix, whilst serving the same function, has the potential to capture and set down areas of slang and unconventional English that have previously been restricted to the status of notes or squeezed into a line or two of Preface and reduced to a mention in passing. Wordless - or non-lexical - slang is one such area of possibility that we have imagined. From our 2005 Preface to the NPDSUE\#1: 'We were tempted but finally chose not to include an appendix of gestures, although many serve the same function as slang' and 'We could not include the obvious pregnant silence that suggests "fuck" ("What the **** do you think you're doing?"). We shied away from the lexicalised animal noises that often work their way into informal conversation, such as a cat noise when someone is behaving nastily. We similarly did not include musical phrases that have become part of our spoken vocabulary, such as the four-note theme of The Twilight Zone which is used to imply an uncanny weirdness in any coincidence, or melodramatic hummed violin music that serves as vocal commentary on a piteous tale.' Online, wordless slang could be enacted and displayed... just imagine.

Wordless slang expressions may be categorised, with little crossover, as aural and gestural, and a core 'vocabulary' gathered with relative ease. However, except where a wordless slang term may be understood and glossed as a variant form of an already existing headword, these items defy further conventional classification. The online environment allows for an active illustration to stand as a headword.

Further samples of an aural list might include:

\begin{abstract}
kiss-teeth; suck-teeth
'[A] ubiquitous and salient sign, rarely written but available as a literary device, in Black and Creole speech communities. It is rich in realizations, discourse functions, interactional contexts and possibilities for sequential organization. Its wide range of meaning, though remarkably unified across the Diaspora, cannot be restricted to negative affect' (Figueroa and Patrick 2002). 'In general, however, the longer and louder the suck-teeth, the more forceful and expressive its "meaning"" (Rickford and Rickford 1980: 357).
\end{abstract}

click-click ( a sharp sucking sound made in the cheek)

Conveys confidence or confident agreement

Sometimes accompanied by a nod and a wink

There is only one essential difference between the two items of wordless slang immediately above: kiss-teeth (and a number of known variants not listed) is widelyrecognised in its 'headword' form or understood from the sense of the words employed; equally, click-click clearly and onomatopoeically represents the action but, despite my best efforts, I could find no actual identifier for this very familiar piece of unconventional English conversation, so I made it up a couple of hours ago. 
My click-click invention is for illustration not suggestion. ${ }^{9}$ If we are to imagine a glossary of aural wordless slang, how then can we organize our collection of terms if they (or some of them at least) remain unnamed? Alphabetical order is unlikely to apply to this 'vocabulary'. Should we look at the slang's sense and group similar terms under thesaurus-like headwords? Relatively simple to do with, say, the single-purposed music-themed terms named above (weirdness, melodrama, and so on), but less so with multi-purposed items like kiss-teeth (disdain, threat, anticipation, etc). Perhaps we could categorise by type of sound involved. Looking again at our two samples, kiss-teeth and click-click are both essentially sucking sounds, which would catalogue them together. However, their senses are so far removed, one from the other, that they border on being opposites. Entirely unsatisfactory. Add into the mix that much of this slang needs to be seen as well as heard but that the visual record of the two samples under consideration here would not be seen to be greatly different and the problem of simple categorisation increases further.

Perhaps I am not yet thinking outside of the book. What I am trying to find is a way to group this (as yet hypothetical) collection of aural wordless slang for casual browsers. A taxonomy will aid easy discovery of the items - but not provide an order in which to catalogue or display them. It's a problem to solve and a problem worth solving.

Gestural slang represents a far larger body of terms than the aural register of wordless expressions. Over the years slang gestures have been partially addressed by other authorities utilising line-drawings with arrows indicating direction of movement and, less lively still, photographs of posed models. Now that the barriers of technology are falling away, fingers crossed, ${ }^{10}$ it should be possible to present a database of gestures as they happen.

My preference is for a short film of an actor demonstrating the gesture. The problem with line-drawings and most photographs is that they neutralise the slang. I spent three weeks of August 2011 at the Edinburgh Festival: much of that time was spent roaming the streets with a video camera, interviewing all kinds of people and filming their gestures. It is readily apparent that the facial expression and body language that accompany the basic movement give sense to the slang. The collected Edinburgh samples underline that awareness. In much the same way that slang words have shades of meaning depending on context and delivery, the meaning of wordless slang often hangs on the subtlety of expression. A slang word can carry a sense of aggression or invitation and the same is true of its unspoken equal. Now, for the first time, a medium in which a dictionary is published has the capability to offer a glossary of active gestures and formal definitions.

There are pitfalls, of course. For instance, the gestures under consideration are bound to English slang and yet may appear in different senses in other cultures:

The clenched hand is extended, with the thumb vertically erect. In English it is better known by the popular name "thumbs up", despite the fact that the action is commonly performed with only one hand. [...] It is not safe to use the "thumbing-a-lift gesture" in either Sardinia or Greece. The message transmitted to the passing drivers by the hopeful 
figures at the roadside is not "please help us", but "get stuffed", and does not encourage drivers to stop, except to pick a fight. (Morris et al. 1979: 195)

\section{thumbs up; thumb up}

1. OK

2. used as a request to hitchhike

Also used, conventionally, as an indicator of direction and, in the context of counting, one.

Incidentally, thumbs up is subject to what is possibly the most widely-held false etymology of them all... but that really is a matter for the online glossary. We presented ourselves with the challenge to imagine future possibilities and discovered that the future is here. Now. The challenge is how to manage all the possibilities we come up with.

A glossary of gestural slang is a reality and we are faced with the problems of categorisation. One suggestion was to include only gestures that might be crossreferenced from existing entries, for instance flip the bird.

\section{flip the bird}

to gesture in derision with a raised middle finger

- Did he flip her the bird again? - Armistead Maupin, Tales of the City, p.344, 1978

- I just flip 'em the bird / And keep goin', I don't take shit from no-one[.] - Eminem (Marshall Mathers) Criminal, 2000

Other headwords also lead to the middle-finger gesture; the list includes sit on it!, spin on it!, spin!, twist! and the punning derivatives Oliver Twist!, Oliver! These variations on a theme demonstrate the playfulness of slang but fail to account for a number of well-established, equally playful variations on the basic middle-finger gesture. So we have a gesture and a subset which might relate only to one point of cross-reference.

A great majority of wordless slang expressions cannot be represented by conventional headwords, as any name given to those expressions is given only for the purposes of identification (see click-click above) and is therefore not a part of the usual business of our dictionary, which is the definition of words in use as part of the slang and unconventional English register.

In current wordless slang there is a significantly widespread trend for elaborate gestural constructs that signal an awkward silence or situation ('this is an awkward situation - let's get out of here/by recognising it we remain aloof'), epitomised by, yet not limited to, the awkward turtle gesture (which exists in a couple of distinct variations) and the awkward palm tree (which actually has its own Facebook ${ }^{\mathrm{TM}}$ page). This gesture is little more than an archly contrived in-group signalling: playful, certainly, probably ironic in intention, but in active circulation. The only way to gain a sufficient understanding of, say, the awkward turtle through the medium of a dictionary must be to see the gesture in action. There is no way to cross-reference to the awkward samples from the body of NPDSUE. 
So, without the alphabet and, by implication, cross-referencing to rely on, how can a harmless drudge organise the entries? Classification and identification might be by:

- derivation/etymology - contrived; imitative; punning; of (likely) sexual origin; from sign language (users of ASL and BSL have generated informal lexical items that have crossed into the gestural slang of non-signers); spoken - that is, gestures that accompany or replace the spoken word; wordless - where the aural and gestural combine (click-click with a wink);

- intent/sense - aggression; comment; inclusion/exclusion; instruction; insult; invitation; etc.;

- physicality - the number of digits (one finger, two fingers, one thumb, etc); the hand(s); when facial expression is more essential not incidental; involvement of other body parts.

The structure of dictionaries has evolved over hundreds of years. The Dictionary (with or without an initial cap) is a very sophisticated register that until now has had to remain within with the limits of a simple wordlist. True, as an obvious exception to prove a rule, there have been visual/pictorial - as opposed to illustrated - dictionaries. These picture dictionaries are themed catalogues, especially valuable for language learners or language outsiders but of limited use here. The only examples of picture dictionaries that I can find in my slang library are humorous or sexual, or both, and significantly - some small volumes dedicated to gesture.

Eric Partridge saw great value in a dictionary's glossaries. An online glossary comprising partially untitled moving images, and which does not have words to play with, is, if not quite terra incognita, certainly an unexplored island of possibilities. In the context of NPDSUE\#2 and the spirit of Partridge it is an imagined possibility.

\section{Interim conclusions}

These reflections and musings (like slang, some serious and some playful) have focussed on the genesis and joys of the New Partridge journey so far. The nuts and bolts of deadlines, meetings and software have been glossed over in this romanticised telling. I have briefly touched upon new content in the updated work. However, the reader of NPDSUE\#1 will know that the world and his wife continue to enrich our language with witty and necessary language and will know what to expect of \#2 - but, without a doubt, the world and his wife have some surprises in store. I have concentrated, certainly in the later parts of this essay, on the challenges presented by the online opportunities. As well as the genesis I have, I hope, offered some revelations.

Perhaps it is not too fanciful to suggest that in a few dictionary generations the educational headword-menagerie will be supplanted by a virtual safari where the genus slang can be seen and understood in its natural habitats. Just imagine. In the meantime, The New Partridge Dictionary of Slang and Unconventional English in its revised and updated Second Edition will be published in hardback and online in August 2012. 


\section{Notes}

1. True, this self-regard may be a relatively benign form of displacement activity but I would argue that proof-checking without the relief of staring distractedly into the past is bad for the eyesight.

2. Isaac Newton's letter to Robert Hooke, February 5, 1675 (Brewster 1855).

3 . For those not actively engaged in the compilation of dictionaries it may seem that selfreference is an inevitable characteristic of reference work. The truth, however, is that most dictionary writers seek, or are obliged, to subsume any but the subtlest trace of self.

4. Tom Dalzell (b.1951) is the author of Flappers 2 Rappers (2010), first published by Merriam-Webster in 1996, and The Slang of Sin (1998).

5. middle-aged adj between youth and old age, variously reckoned to suit the reckoner $(C 21 D)$.

6. The figure given by Dr Hamadoun Touré, Secretary General of the International Telecommunication Union (ITU) 'Brief Remarks to the Media', 26th January 2011. He also noted 5 billion mobile cellular subscriptions.

7. Sixteen-year-old Welsh girl (2011).

8. In the semi-conventional world of emoticons $>; 3$ is recorded as a winking cat. When discussing emotions of this type it is hard to resist the punning quality of a parenthesis :-)

9. It is not for the likes of us, the recorders of language, to make words up. Is it?

10. Fingers crossed is a superstitious gesture based on a pre-Christian understanding of the cross. It is a mainly conventional idiom although it may appear somewhat slangy when in childish use as the cancellation of a promise.

\section{References}

AHD4 = The American Heritage Dictionary of the English Language. (2000). 4th ed. Boston: Houghton Mifflin.

Anglicus, Ducange [pseud. of Bernard Quaritch] (1857): The Vulgar Tongue: Comprising Two Glossaries of Slang, Cant, and Flash Words and Phrases. London: B. Quaritch.

Brewster, David (1855): Memoirs of the Life, Writings, and Discoveries of Sir Isaac Newton. Edinburgh: T. Constable \& Co.

Brophy, John and Eric Partridge (1930): Songs and Slang of the British Soldier: 1914-1918 . London: Eric Partridge Ltd. at the Scholartis Press.

$C 21 D=$ Chambers 21 st Century Dictionary. (1999). Edinburgh: Chambers.

COED11 = Concise Oxford English Dictionary. (2004). 11th ed. Oxford: Oxford University Press.

Crystal, David. 2004. A Glossary of Netspeak and Textspeak. Edinburgh: Edinburgh University Press.

Dalzell, Tom (2010): Flappers 2 Rappers: American Youth Slang. 2nd ed. New York: Dover. (1st ed. 1996).

Dalzell, Tom and Terry Victor (2006): The New Partridge Dictionary of Slang and Unconventional English. London: Routledge.

- (2008a): Sex Slang. London: Routledge.

(2008b): Vice Slang. London: Routledge. 
(2012): The New Partridge Dictionary of Slang and Unconventional English. 2nd revised ed. London: Routledge.

Dent, Susie (2006): The (like, Language Report (for real). Oxford: Oxford University Press.

DSUE = Partridge, Eric (1937).

Dury, Ian (1977): 'Sex and Drugs and Rock and Roll'. (Song). London: Stiff Records.

Farmer, John S. and W. E. Henley (1890-1904): Slang and Its Analogues Past and Present. 7 vols. London: Printed for subscribers only. (Vol. 1 comp. and ed. by John S[tephen] Farmer; vols 2-7 comp. and ed. by John S[tephen] Farmer and W[illiam] E[rnest] Henley).

Figueroa, Esther and Peter L. Patrick (2002): 'The Meaning of Kiss-Teeth'.

$<$ http://privatewww.essex.ac.uk/ patrickp/papers/KSTpapwww.pdf>. (Accessed October 2011).

Forsyth, Mark ('The Inky Fool') (2011): The Etymologicon. London: Icon Books.

Greenough, James Bradstreet and George Lyman Kittredge (1901): Words and Their Ways in English Speech. New York: Macmillan.

Grose, Francis (1785): A Classical Dictionary of the Vulgar Tongue. London: S. Hooper.

Hotten, John Camden (1865): The Slang Dictionary; or, The Vulgar Words, Street Phrases, and "Fast" Expressions of High and Low Society. London: John Camden Hotten.

Jackson, Howard (2002): Lexicography: An Introduction. London: Routledge.

Johnson, Samuel (1755): A Dictionary of the English Language. 2 vols. London: W. Strahan.

Lewis, Angela (PhD) (2010): My Other Self. Brisbane, Qld: Book Pal.

Morris, Desmond et al. (1979): Gestures: Their Origins and Distribution. London: Jonathan Cape.

NPDSUE\# 1 = Dalzell, Tom and Terry Victor (2006).

NPDSUE\#2 = Dalzell, Tom and Terry Victor (2012).

Partridge, Eric (1937): A Dictionary of Slang and Unconventional English. London: George Routledge \& Sons, Limited. (8 editions: lst ed. 1937; Supplement, 1938; 2nd ed. 1938; 3rd ed. 1949; 4th ed. 1951; 5th ed., 2 vols, 1961; 6th ed., 2 vols, 1967; 7th ed., 2 vols, 1970; 8th ed., 1 vol., 1984 [Routledge \& Kegan Paul], commenced in collaboration with, and completed by, by Paul Beale.)

(1945): A Dictionary of R.A.F. Slang. London: Michael Joseph.

(1948): Words at War, Words at Peace. London: Frederick Muller.

(1949): A Dictionary of the Underworld, British \& American. London: Routledge \& Kegan Paul.

- (1955): Shakespeare's Bawdy. New popular edition, revised. London: Routledge \& Kegan Paul.

- (1963): The Gentle Art of Lexicography, As Pursued and Experienced by an Addict. London: André Deutsch.

Popcorn, Faith and Adam Hanft (2001): Dictionary of the Future. New York: Hyperion.

Rickford, John R. and Angela E. Rickford (1980): 'Cut-Eye and Suck-Teeth: African Words and Gestures in New World Guise'. In Joey Lee Dillard (ed.), Perspectives on American English. The Hague: Mouton De Gruyter. 347-365. 